\title{
High-resolution linkage mapping for the non-brittle rachis locus btrl in cultivated $x$ wild barley (Hordeum vulgare)
}

\author{
Perumal Azhaguve ${ }^{a}$, Dhanasekaran Vidya-Saraswathi, ${ }^{a, b}$ Takao \\ Komatsuda ${ }^{a, *}$
}

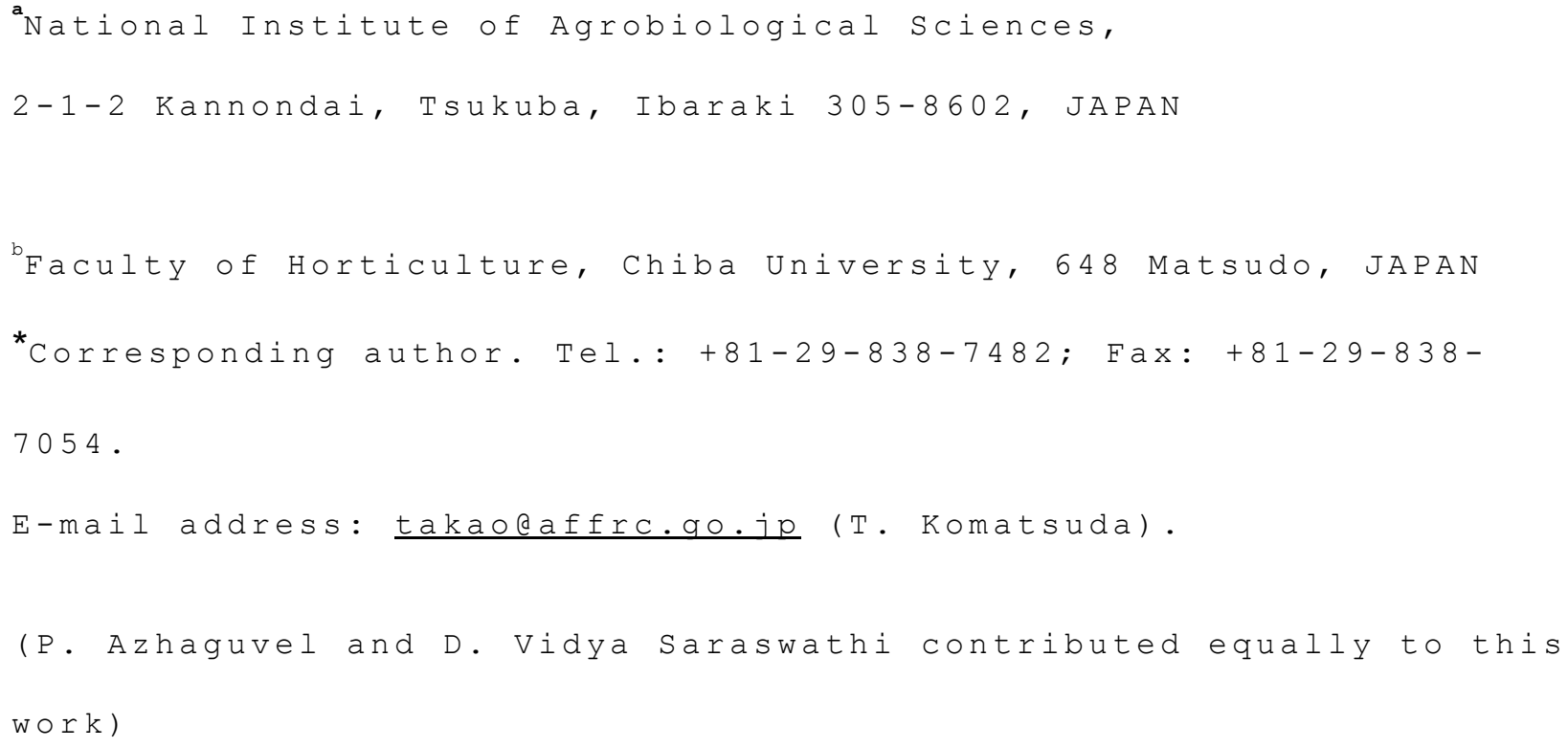

\section{Abstract}

Brittle rachis is an important trait to elucidate the domestication process in barley. Brittle rachis in wild barley (Hordeum vulgare ssp. spontaneum (C. Koch.) Thell) is controlled 


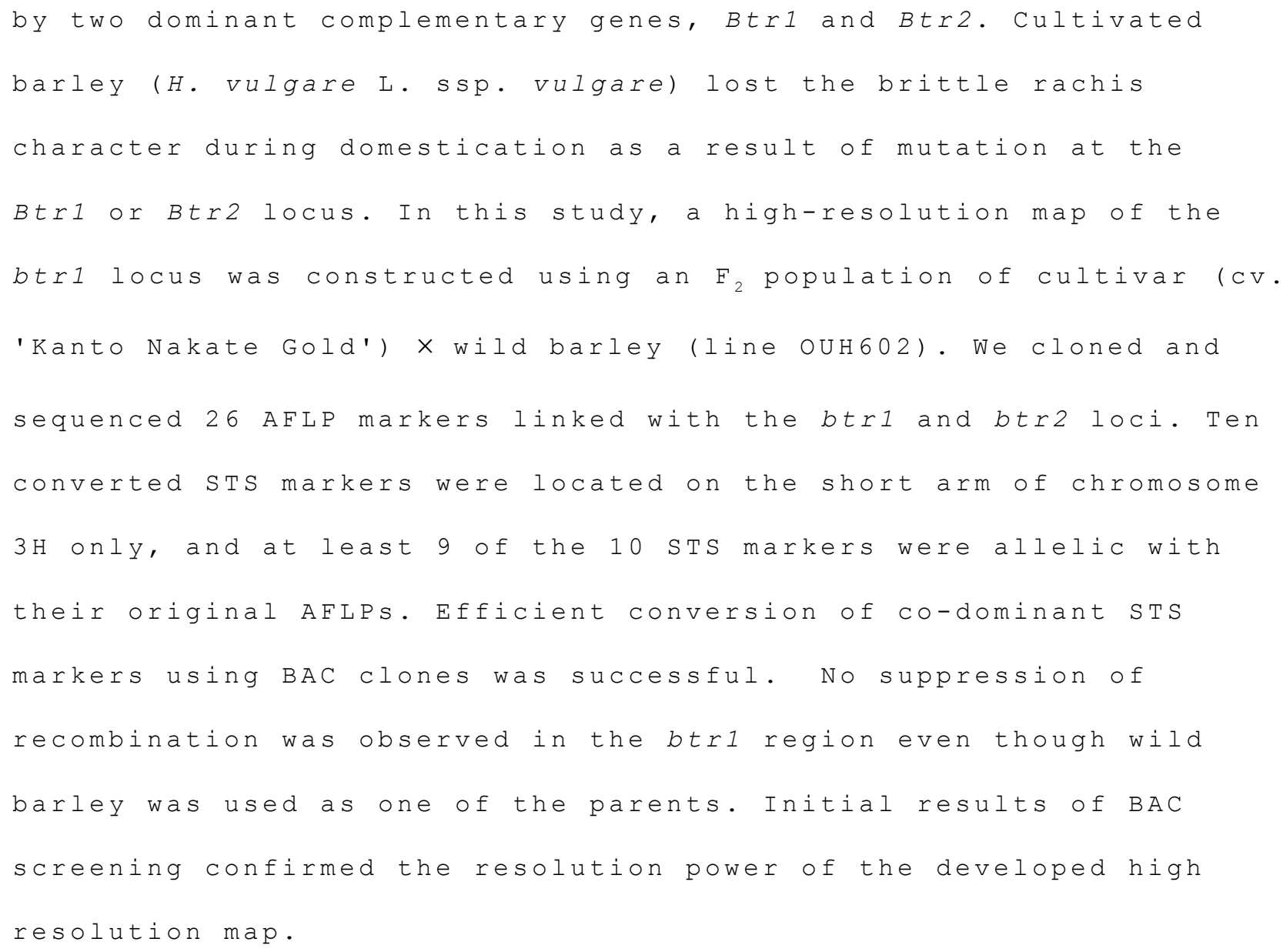




\section{Introduction}

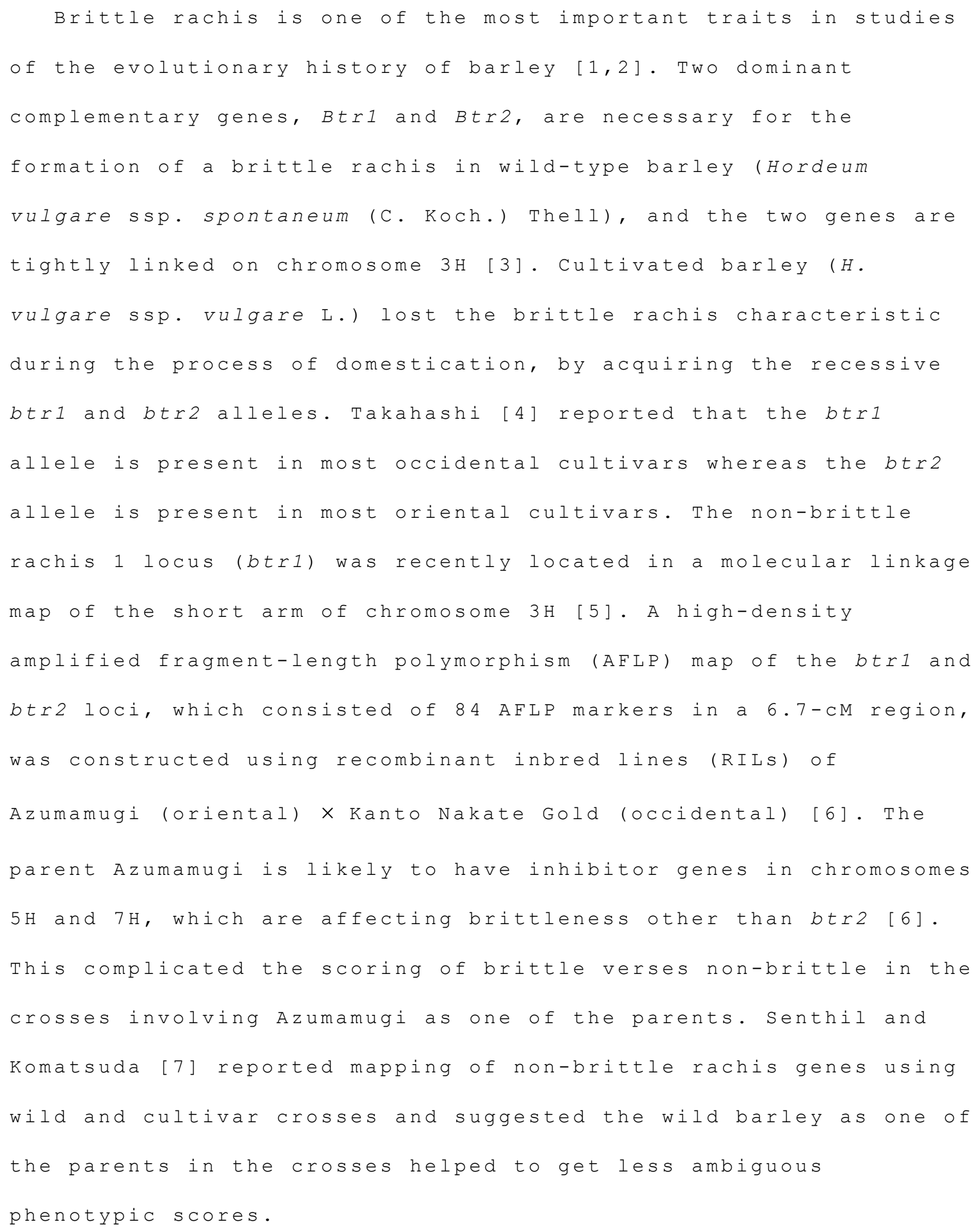




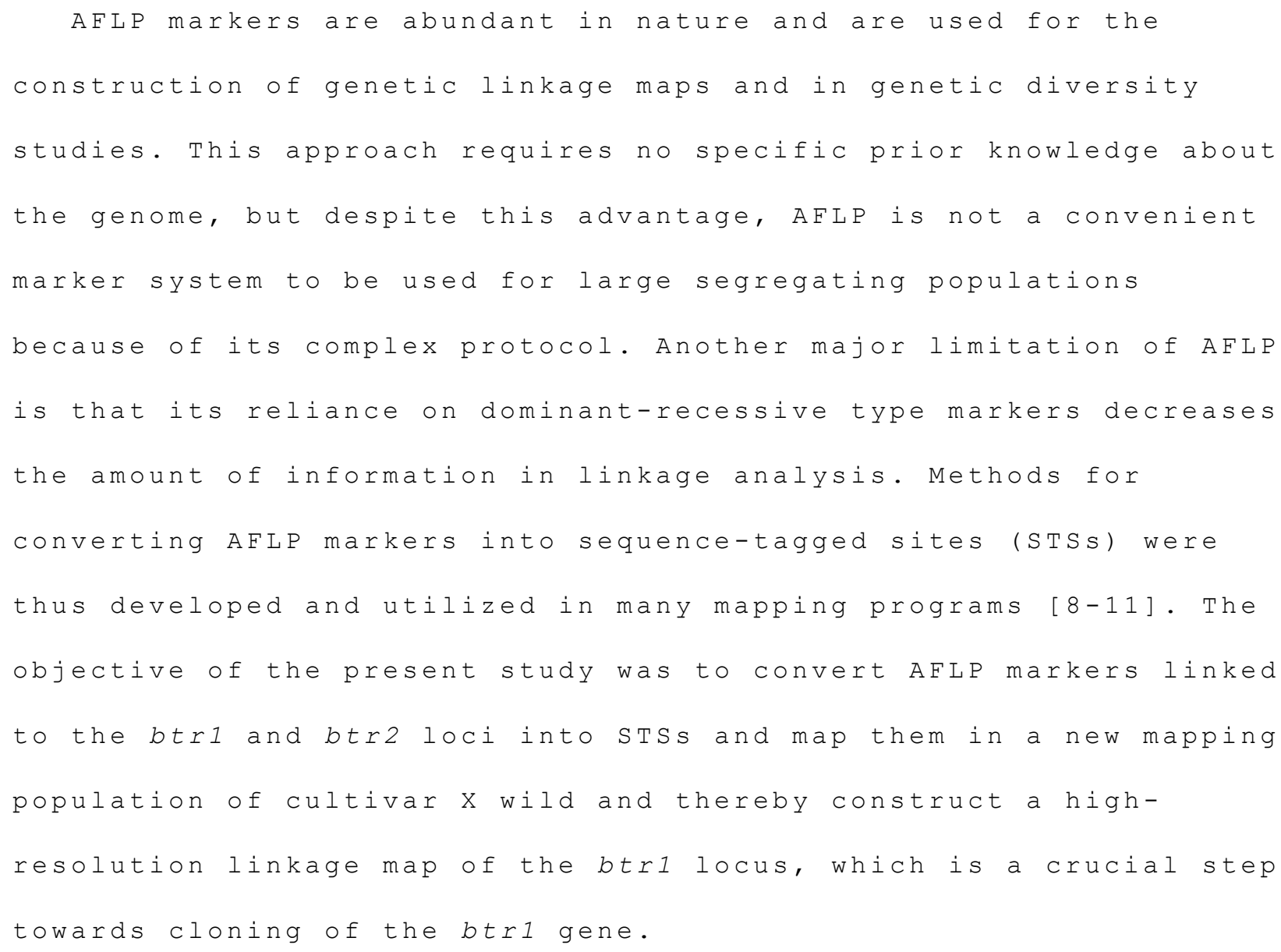

\section{Materials and Methods}

\subsection{Plant material}

Seeds of the 'Azumamugi' (AZ) and 'Kanto Nakate Gold' (KNG)

cultivars were obtained from the Barley Breeding Laboratory of the National Institute of Crop Science, Tsukuba. Az is a sixrowed cultivar with a BtrlBtrlbtr2btr2 genotype and KNG is a tworowed cultivar with a btrlbtrlBtr2Btr2 genotype. Seeds of a wild barley line 'OUH602' (OUH) were obtained from the Research Institute for Bioresources of Okayama University, Kurashiki. OuH 


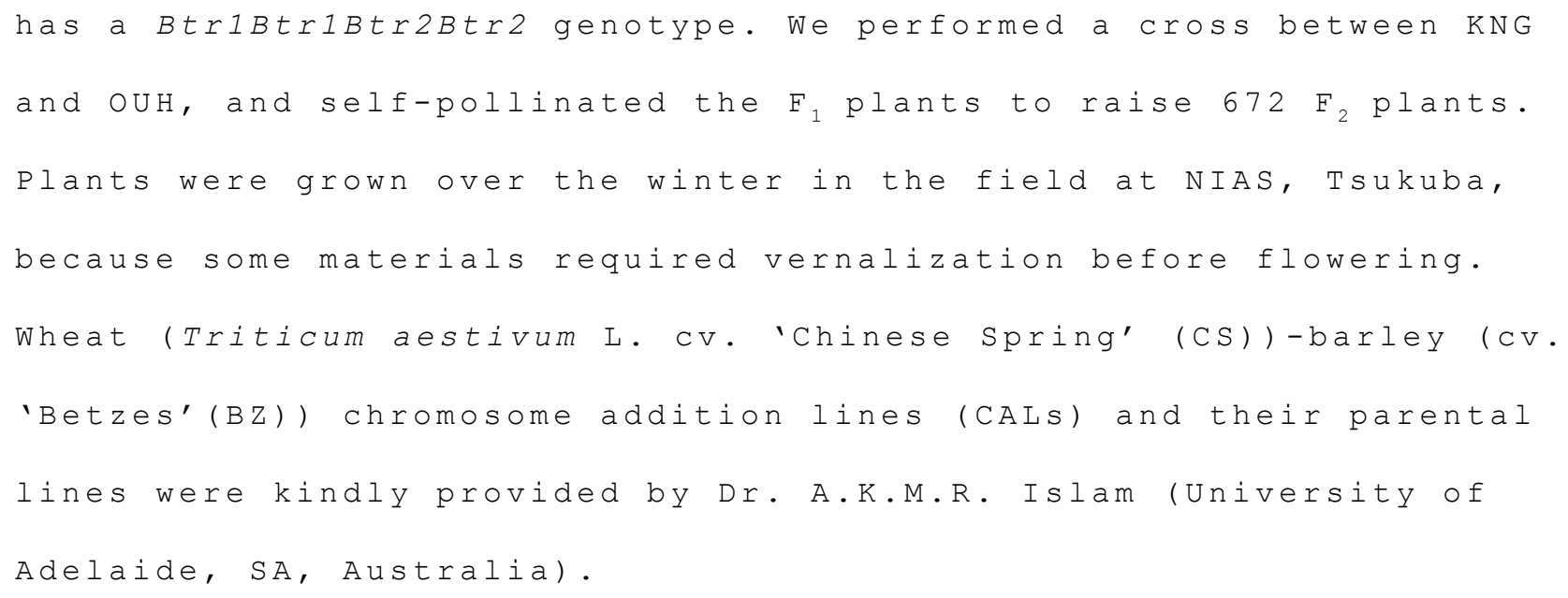




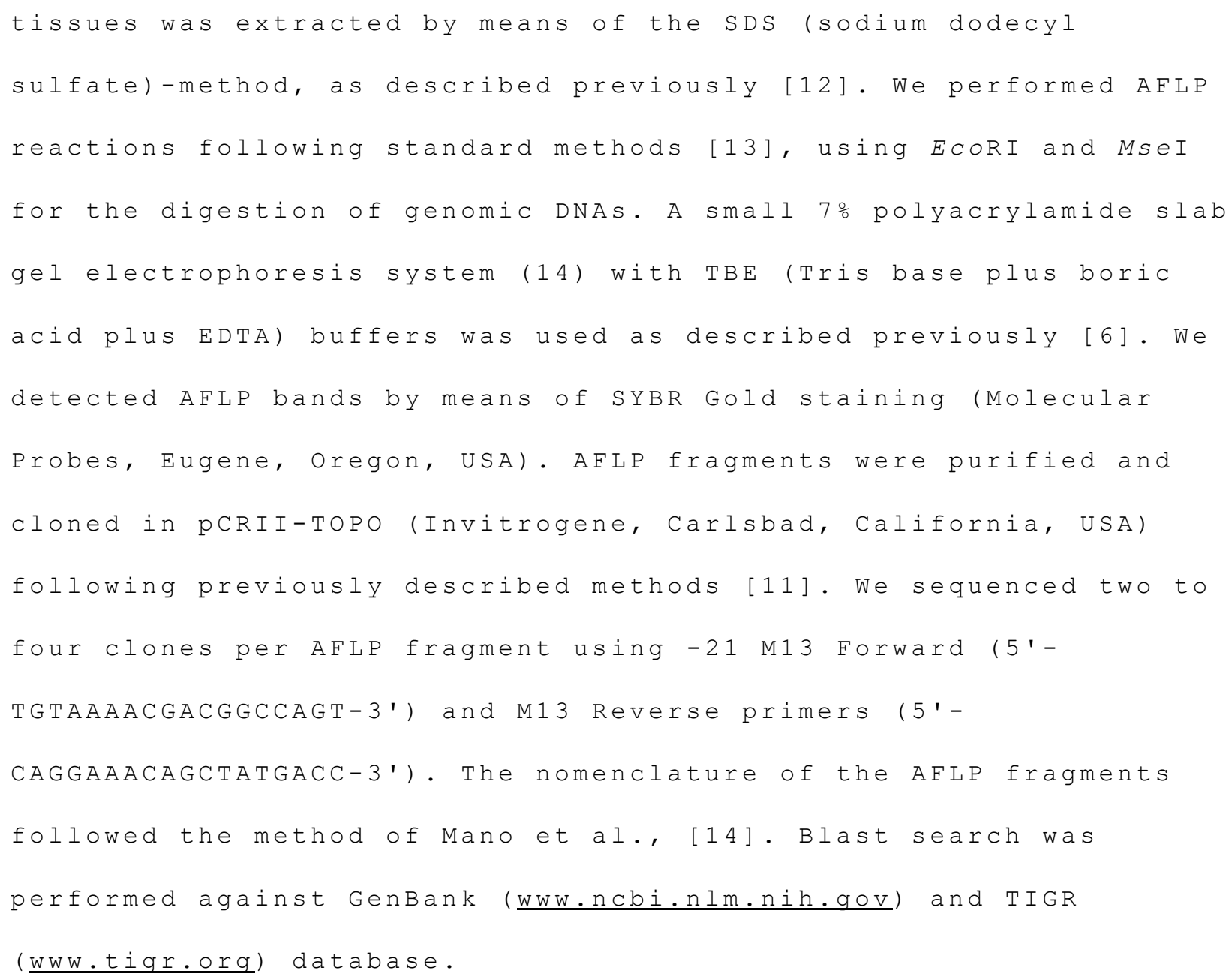




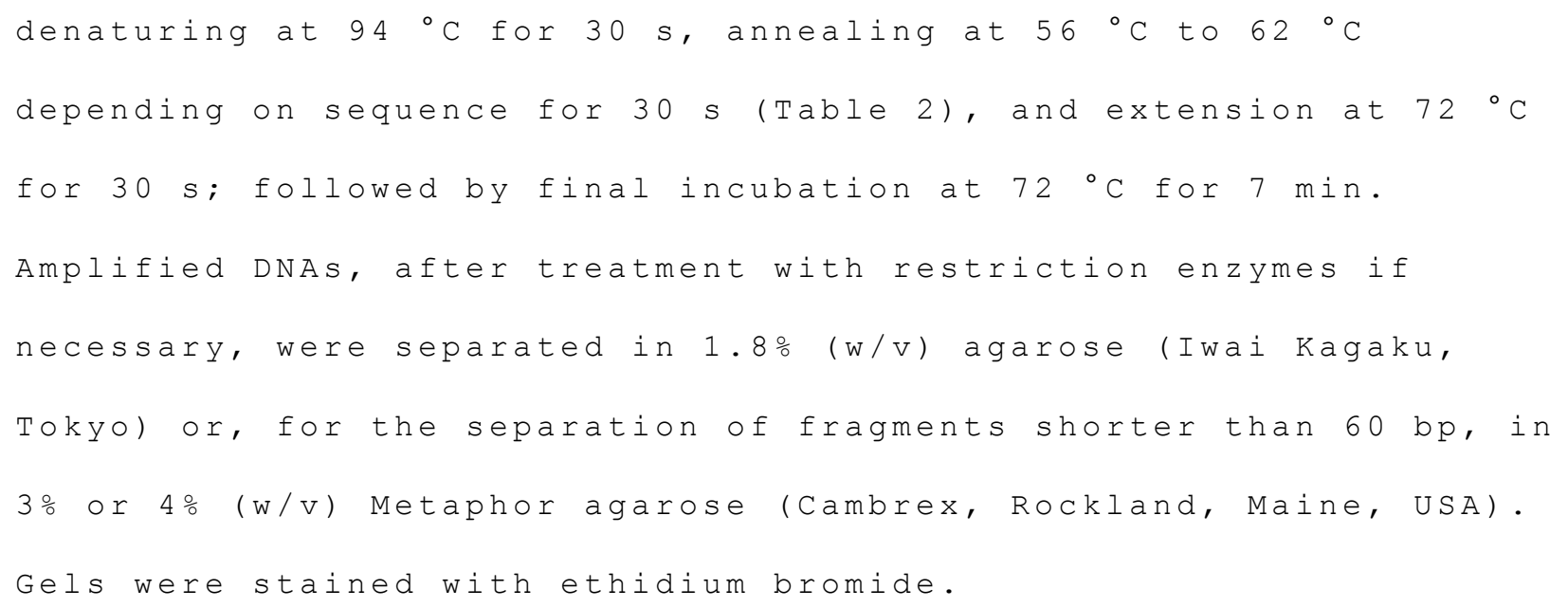




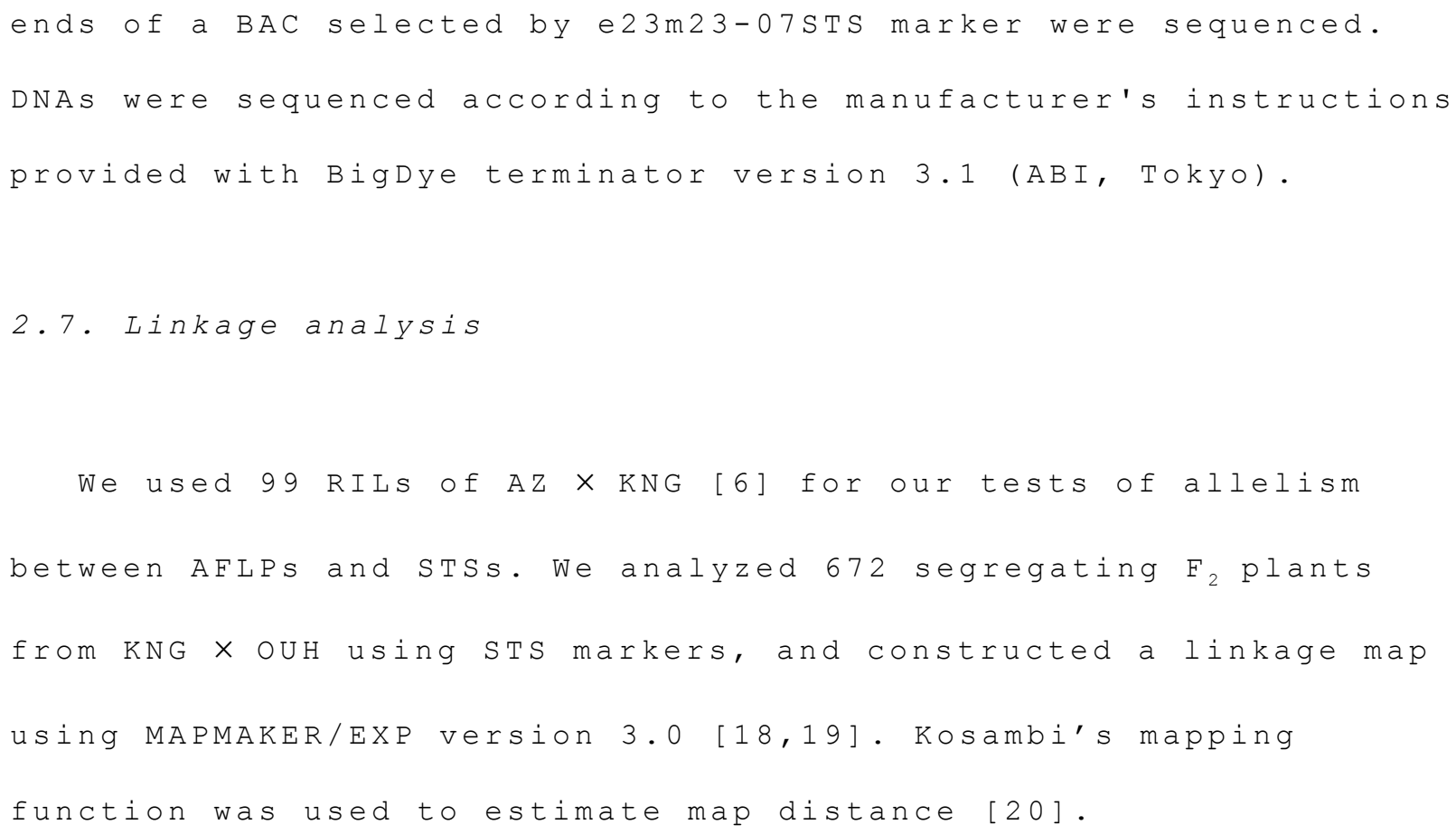

\section{Results}

3.1. DNA Sequences of AFLP fragments

DNA sequences of 26 AFLP fragments previously linked to btr1/btr2 loci $[6,7]$ were determined (Table 1). The sizes ranged between 81 and $1247 \mathrm{bp}$. All the fragments contained an ECORIadapter sequence on one end and an Mser-adapter sequence on the other end. Blastn search for the DNA sequences against the GenBank revealed 10 AFLP fragments to be homologous with Triticeae retrotransposons (Table 1). A blastn search against TIGR ("Gramineae Repeat") showed almost the same result (data not shown). Translated sequences revealed no significant homologies for all AFLP sequences in protein database by blastx with the exception of e50m21-01 (4 $\left.e^{-10}\right)$ and e57m10-07 (4 e $e^{-24}$ which showed 


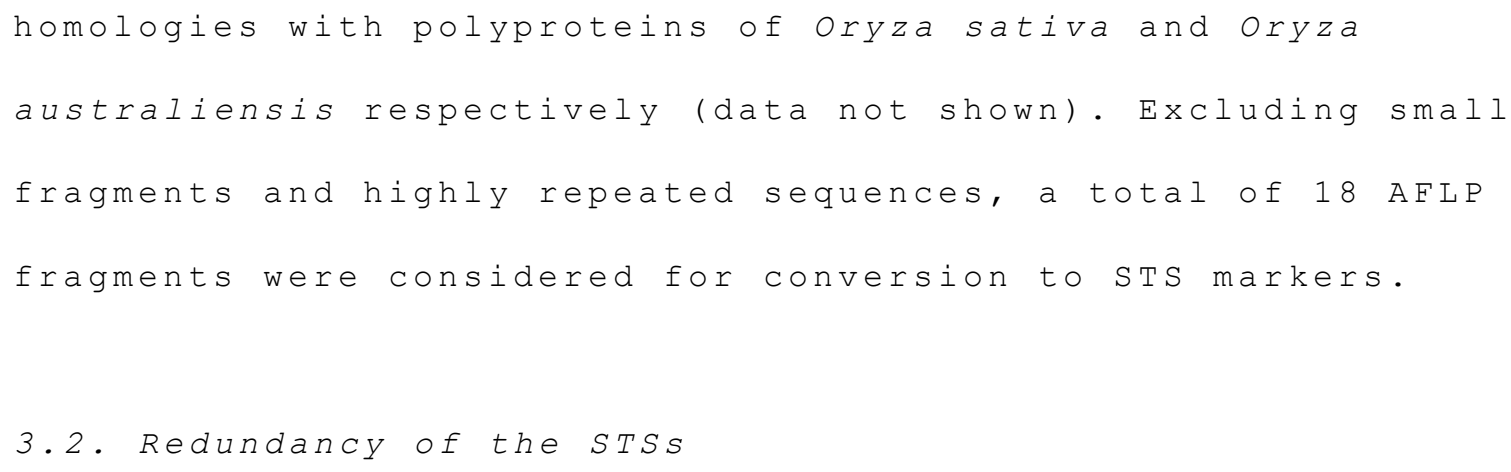




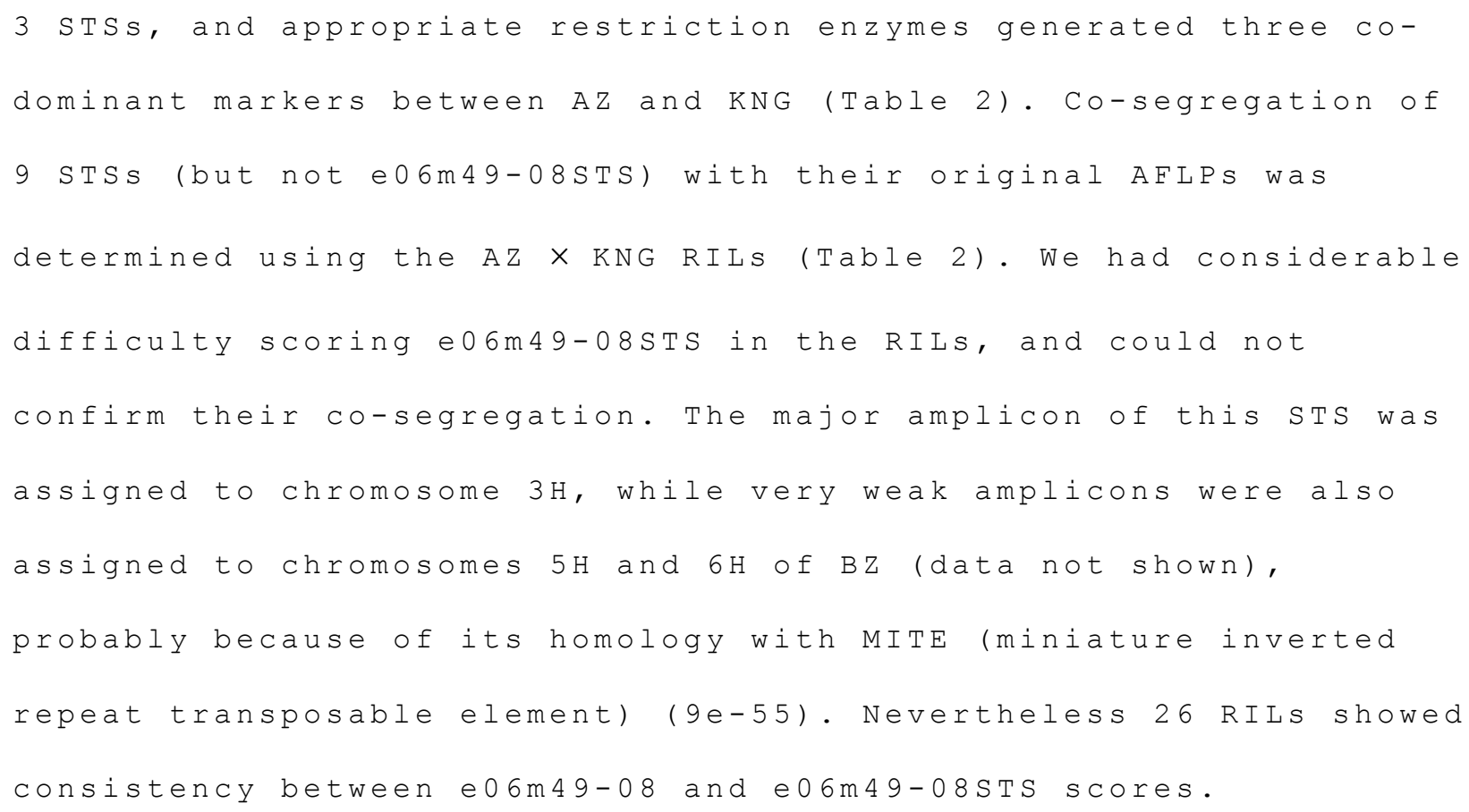

3.4. High-resolution mapping using the KNG $x$ OUH Fr population

Developed dominant and co-dominant STS markers were used to analyze the KNG $\times$ OUH 672 segregating $F_{2}$ plants (Table 2). Initially, we used four STS markers: The e05m15-09STS and e39m2311STS markers apparently flanked the btrl locus in the Az $\times$ KNG population (Fig. 1a), but they were dominant markers (Table 2 ) . The orientation of e23m23-07STS and e50m21-01stS with respect to btrl was not clear in the AZ $\times$ KNG population (Fig. 1a), but they were co-dominant markers (Table 2) and expected to recombine with the btrl locus in the large-scale KNG $\times$ OUH F population. The segregation ratio of all four markers did not significantly deviate from the expected 3:1 or 1:2:1 ratio, but each deviated 


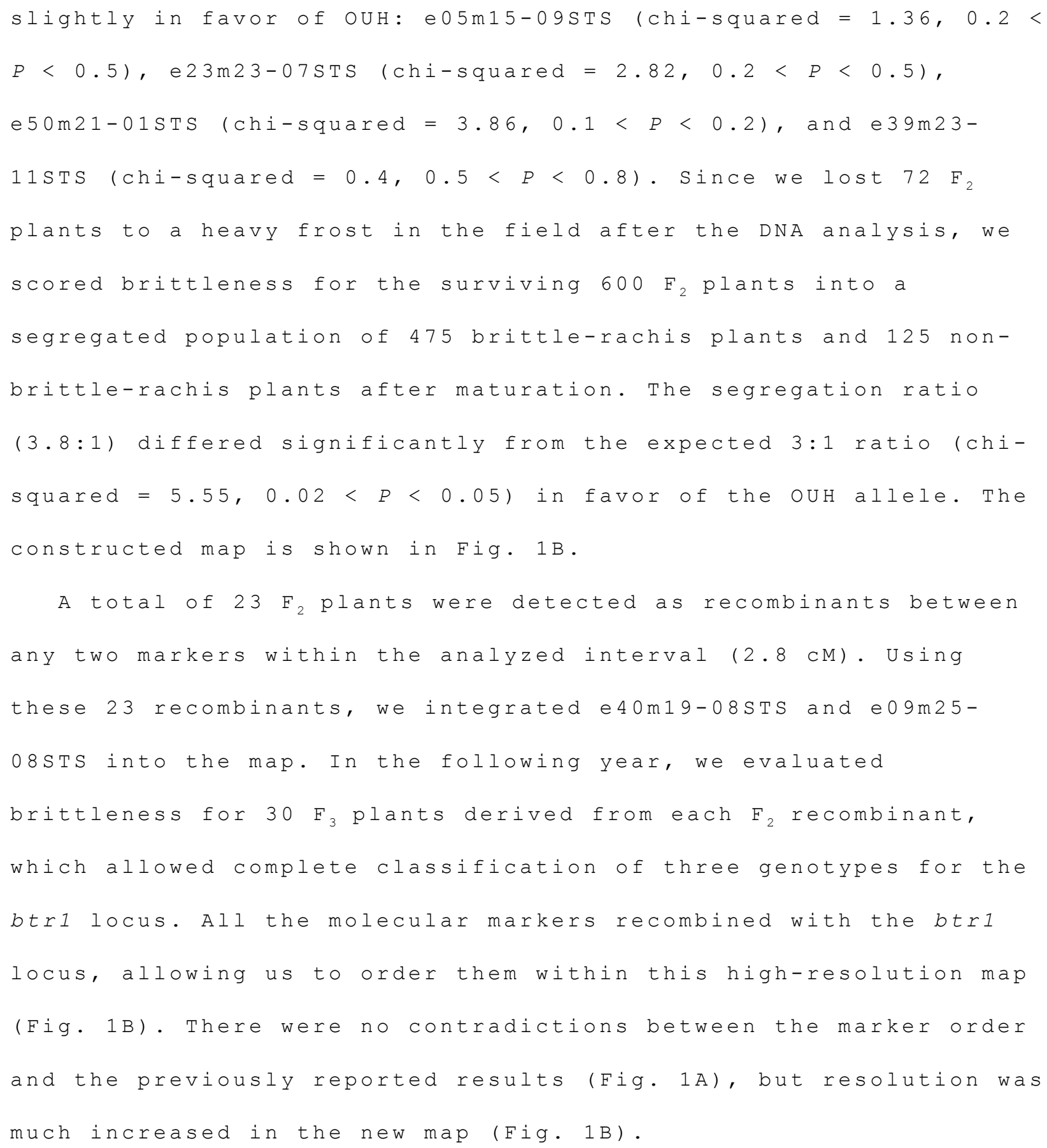




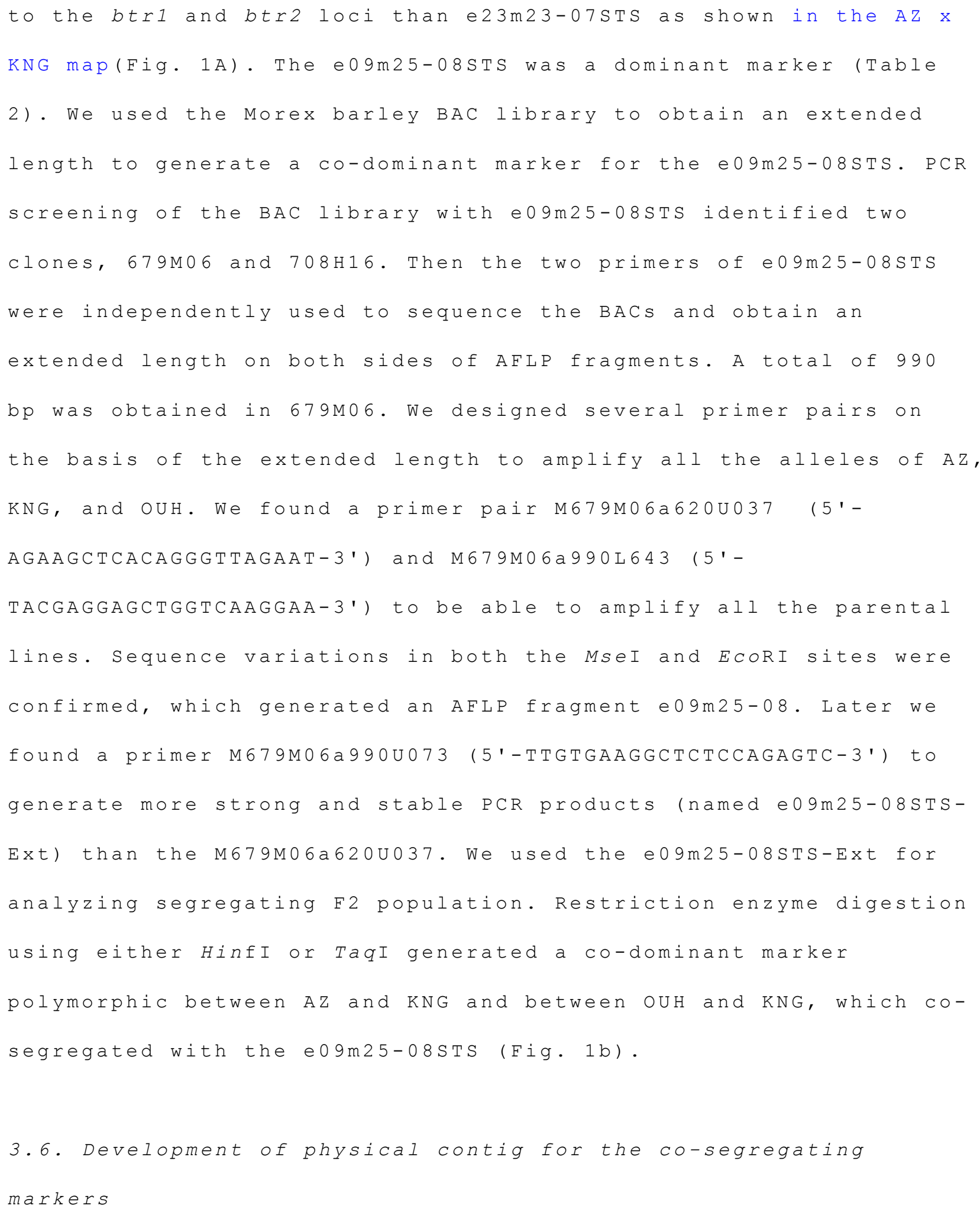


The STS markers e09m25-08STS and e23m23-07STS are cosegregating in the high-resolution map (Fig. 1). A physical contig was constructed to evaluate the resolution power of the genetic map. The STS marker e09m25-08 identified two BAC clones $679 \mathrm{~J} 21$ and 708H16, whereas e23m23-07STS identified $174 \mathrm{~J} 19$ and 592A03. End-sequence of the 679J21 was converted to a PCR marker 679 J21-R-STS using primers 5' - TAGCTATCAATAAGTCCATC - $3^{\prime}$ and $5^{\prime}-$ GTACAGTGACTAAATGCATG - $3^{\prime}$. The 679J21-R-STS co-segregated with e09m25-08STS and e23m23-07STS, and hit the 174J19 and 708H16, which allowed connection of the two BAC contigs (Fig. 1 ).

\section{Discussion}

AFLP markers were converted into stss to exploit the potentiality of simple and co-dominant nature of STS markers [811]. The Pst-MseI combination was more efficient than the EcoRIMseI combination for detecting AFLPs in barley and maize [21, 22], whereas the difference was not significant in wheat [23]. Since Pst is sensitive to methylation, it has been assumed that using Pst would decrease the ratio of repetitive DNA sequences in cereal AFLPs $[10,24,25]$. However, few AFLPs were converted to STS in these studies. Shan et al. [26] cloned 26 AFLP markers generated by means of the EcoRI-MseI combination in wheat or barley, and were able to develop 6 stss markers (23\%) that could be assigned to specific chromosomes. In the present study, the efficiency of the conversion was $38 \%(10 / 26)$. He et al. [11] successfully convertedall five AFLP fragments in their study, 


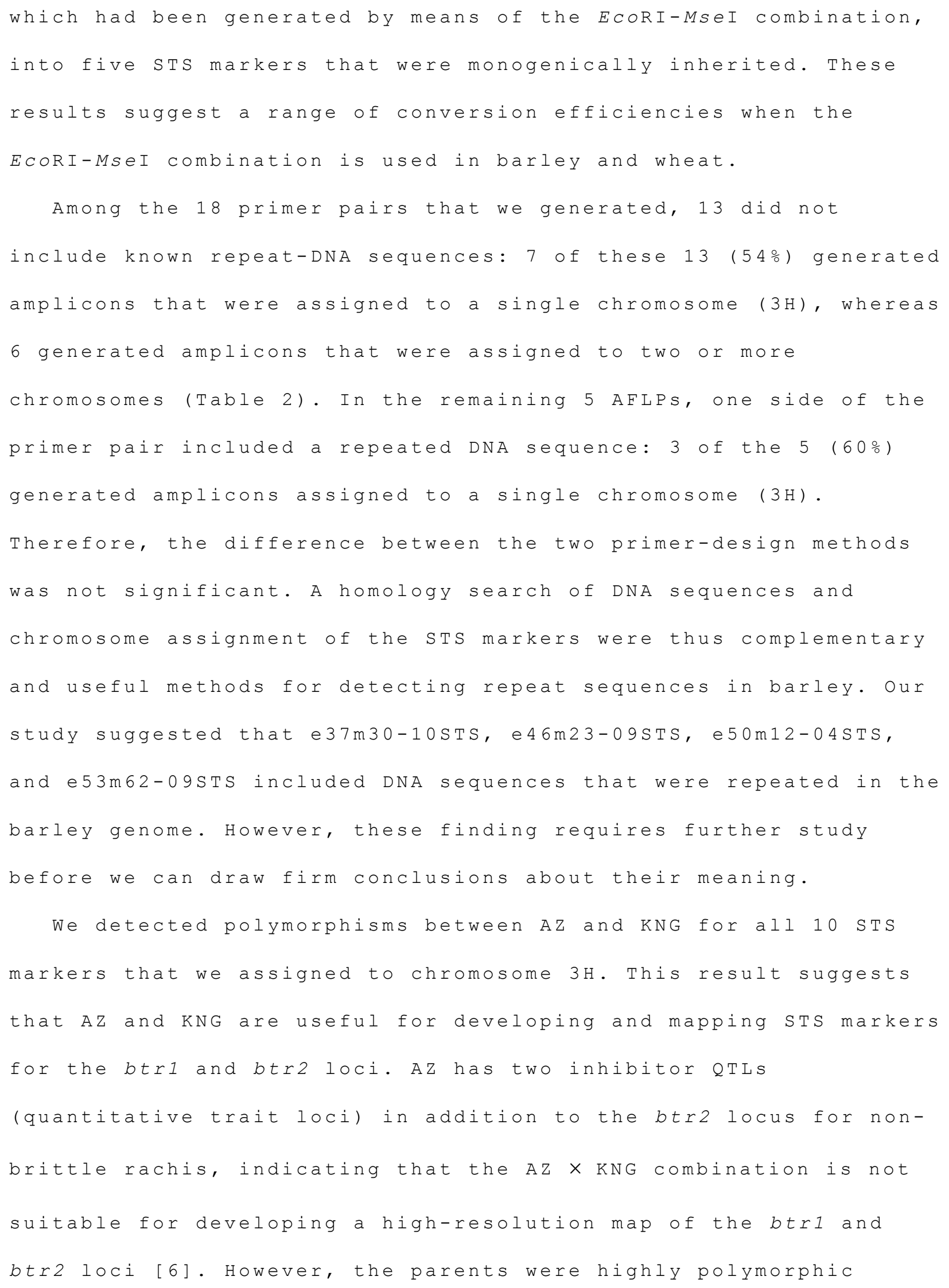




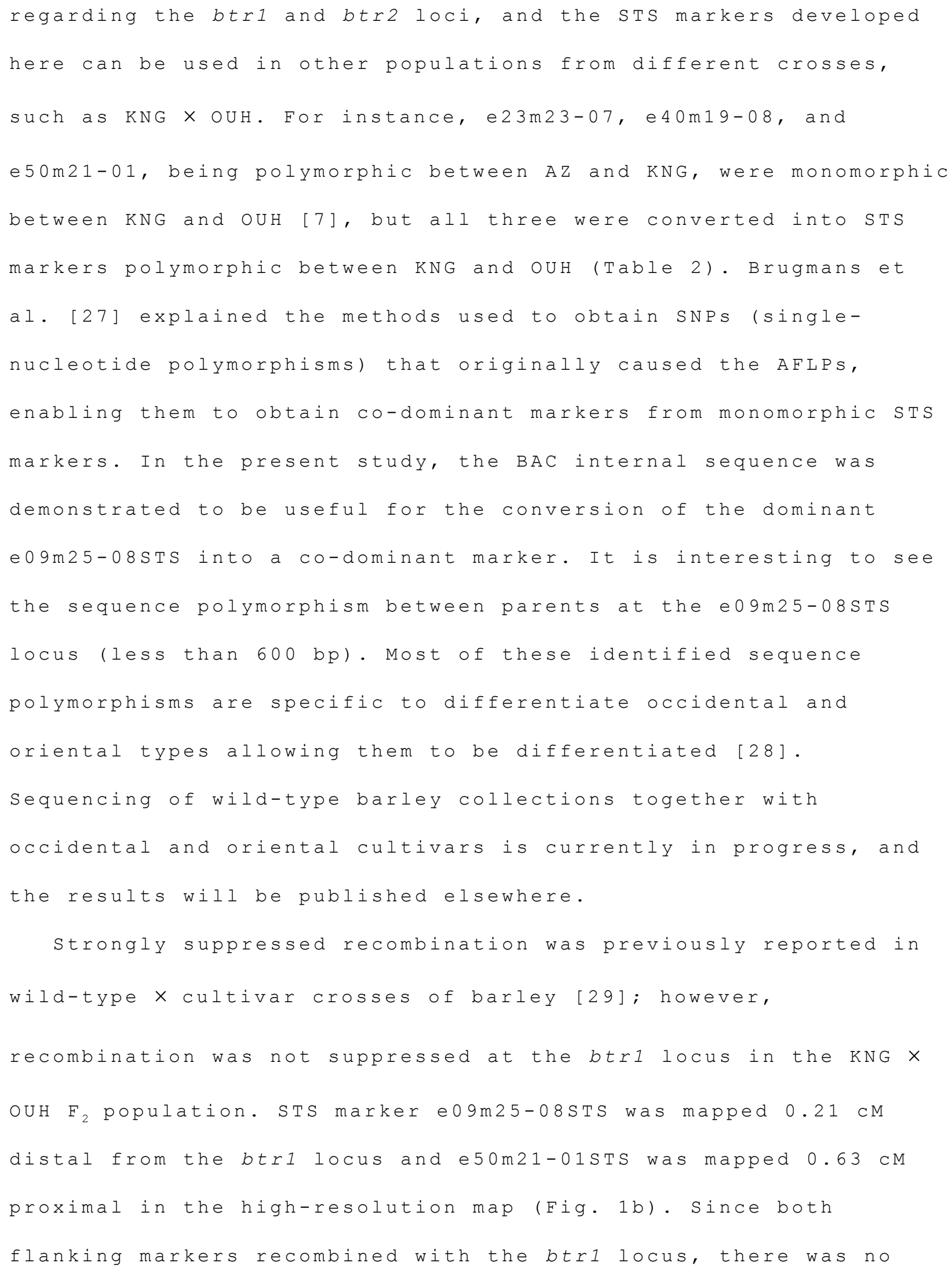


evidence to suppose the existence of chromosomal rearrangement at the btrl locus, at least not between KNG and OUH.

Initial BAC screening results suggested reasonable resolution power of the present genetic map, as we aligned physical contig for the co-segregating markers. künzel et al. [30] reported increased recombination in the marker interval between MWG577 and ABG462 region of $3 \mathrm{HS}$. The btrl/btr2 region falls under this marker interval and the estimated physical/genetic distance ratio was 1.0-4.4 Mb/cM [30]. The average size of each BAC is $100 \mathrm{~kb}$ [16], so the physical distance between e09m25-08STS and e23m2307STS should be a maximum of $200 \mathrm{~kb}$. Although there were no recombinations between the two markers, one recombination will make the map distance of 0.07 cM, therefore physical/genetical ratiofor this region can be estimated minimum $200 \mathrm{~kb} / 0.07 \mathrm{~cm}=$ 3Mb/cM. However, it is difficult to prove the hypothesis rate of recombination unless the completion of contig of btrl flanking markers. The new co-dominant STS markers e09m25-08STS-Ext and e50m21-01STS still flank a 0.84 cM and the markers may not be optimal to start chromosome walking. Since barley chromosome 3 H and rice chromosome 1 are colinear over their entire length [31,32], marker enrichment could be achieved by using barley EsT resources and barley-rice colinearity. Ten AFLP markers cosegregated with the btrl and btr2 loci [6] and we were able to convert only four of them in this study, but remaining six were not because of their small fragments or repeated elements. These six AFLPs can be used for fine mapping, but five of the six AFLPs were monomorphic between KNG and OUH. The population of 672 F 


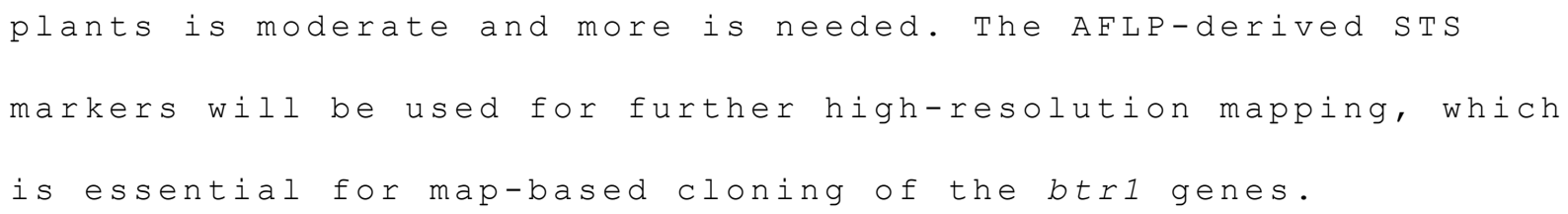

\section{Acknowledgments}

The authors thank Dr. N. Senthil, Dr. Congfen He, and Dr. Y. Turuspekov of our laboratory for their technical assistance and suggestions in our laboratory protocols, and Mr. M. Sameri of our laboratory for his assistance in our field experiments. This study was supported in part by the CREST program of the Japan Science and Technology Corporation (JST). P. Azhaguvel was a research fellow supported by the Japan society for the Promotion of Science ( JSPS).

\section{References}

[1] R. Takahashi, The origin and evolution of cultivated barley, in: M. Demerec, (ed.), Advances in Genetics, vol. 7, Academic, New York, 1955, pp. 227-266.

[2] Rv. Bothmer, N. Jacobsen, Origin, taxonomy, and related species. in: D. Rasmusson (ed.), Barley. ASA Agronomy Monograph, vol. 26, American Society of Agronomy, Crop Science Society of America, Soil Science Society of America, Madison, 1985, pp. 19-56. 
[3] R. Takahashi, J. Hayashi, Linkage study of two complementary genes for brittle rachis in barley, Ber Ohara Inst Landwirtsch Biol. Okayama Univ. 12 (1964) 99-105.

[4] R. Takahashi, Further studies on the phylogenetics differentiation of cultivated barley, Barley Genetics 1 (1963) $19-26$.

[5] T. Komatsuda, Y. Mano, Molecular mapping of the intermedium spike-c (int-c) and non-brittle rachis 1 (btrl) loci in barley (Hordeum vulgare L.), Theor. Appl. Genet. 105 (2002) $85-90$.

[6] T. Komatsuda, P. Maxim, N. Senthil, Y. Mano, High-density AFLP map of nonbrittle rachis 1 (btrl) and 2 (btr2) genes in barley (Hordeum vulgare L.), Theor. Appl. Genet. 109 (2004) $986-995$.

[7] N. Senthil and T. Komatsuda, Comparative mapping of nonbrittle rachis genes btrl and btr2 using wild $x$ Occidental and wild $x$ oriental cultivar populations in barley Hordeum vulgare L., Euphytica 145 (2005) 215-220.

[8] N.G. Paltridge, N.C. Collins, A. Bendahmane, R. H. Symons, Development of YLM, a co-dominant PCR marker closely linked to the Yd2 gene for resistance to barley yellow dwarf disease, Theor. Appl. Genet.96 (1998) 1170-1177.

[9] L. Decousset, S. Griffiths, R.P. Dunford, N. Pratchett, D.A. Laurie, Development of STS markers closely linked to the Ppd-HI photoperiod response gene of barley (Hordeum vulgare L.), Theor. Appl. Genet. 101 (2000) 1202-1206. 
[10] J.S. Weerasena, B.J. Steffenson, A.B. Falk, Conversion of an amplified fragment length polymorphism marker into a codominant marker in the mapping of the Rphl5 gene conferring resistance to barley leaf rust, Puccinia hordei otth., Theor. Appl. Genet. $108(2003) \quad 712-719$.

[11] C. He, B.E. Sayed-Tabatabaei, T. Komatsuda, AFLP targeting of the 1-cM region conferring the vrsl gene for six-rowed spike in barley, Hordeum vulgare L., Genome 47(2004)11221129.

[12] T. Komatsuda, I. Nakamura, F. Takaiwa, S. Oka, Development of STS markers closely linked to the vrsl locus in barley, Hordeum vulgare, Genome 41 (1998) 680-685.

[13] P. Vos, R. Hogers, M. Bleeker, M. Reijans, T. van de lee, M. Hornes, A. Frijters, J. Pot, J. Peleman, M. Kuiper, M. Zabeau, AFLP: a new technique for DNA fingerprinting, Nucleic Acids Res. 23(1995) 4407-4414.

[14] Y. Mano, S. Kawasaki, F. Takaiwa, T. Komatsuda, Construction of a genetic map of barley (Hordeum vulgare L.) cross 'Azumamugi'x 'Kanto Nakate Gold' using a simple and efficient amplified fragment-length polymorphism system, Genome 44 (2001) 284-292.

[15] J.D. Thompson, D.G. Higgins, T.J. Gibson, CLUSTAL W: improving the sensitivity of progressive multiple sequence alignment through sequence weighting, position specific gap penalties and weight matrix choice, Nucleic Acid Res. 22 (1994) 4673-4680. 
[16] Y. Yu, J.P. Tomkins, R. Waugh, D.A. Frisch, D. Kudrna, A. Kleinhofs, R.S. Brueggeman, G.J. Muehlbauer, R.P. Wise, R.A. Wing, A bacterial artificial chromosome library for barley (Hordeum vulgare L.) and the identification of clones containing putative resistance genes, Theor. Appl. Genet. $101(2000) \quad 1093-1099$.

[17] J. Sambrook, D.W. Russel, Molecular cloning: a laboratory manual. 3rd edn. Cold spring Harbor Laboratory, Cold spring Harbor, New York, 2001 .

[18] E.S. Lander, P. Green, J. Abrahamson, A. Barlow, M.J. Daly, S.E. Lincoln, L. Newburg, MAPMAKER: An interactive computer package for constructing primary genetic linkage maps of experimental and natural populations, Genomics 1 (1987) 174181

[19] S.E. Lincoln, M.J. Daly, E.S. Lander, Constructing genetic linkage maps with MAPMAKER/EXP 3.0. Whitehead Institute for Biomedical Research Technical Report, Cambridge, 1993.

[20] D. Kosambi, The estimation of map distances from recombination values, Ann. Eugen. 12 (1944) 172-175.

[21] W. Powell, W. T.B. Thomas, E. Baird, P. Lawrence, A. Booth, B. Harrower, J.W. McNicol, R. Waugh, Analysis of quantitative traits in barley by the use of amplified fragment length polymorphisms, Heredity 79 (1997) $48-59$.

[2 2 ] M. Vuylsteke, R. Mank, B. Brugmans, P. Stam, M. Kuiper, Further characterization of AFLP ${ }^{\circledR}$ data as a tool in genetic diversity assessments among maize (zea mays L.) inbred lines, Mol Breed $6(2000) 265-276$. 
[23] B.A. Barrett, K.K. Kidwell, AFLP-based genetic diversity assessment among wheat cultivars from the Pacific Northwest, Crop Sci. $38(1998) \quad 1261-1271$

[24] Y.G. Cho, M.W. Blair, O. Panaud, S.R. McCouch, Cloning and mapping of variety-specific rice genomic DNA sequences: amplified fragment length polymorphism (AFLP) from silverstained polyacrylamide gels, Genome 39 (1996) 373-378.

[25] R. Prins, J.Z. Groenewald, G.F. Marais, J.W. Snape, R.M.W. Koebner, AFLP and STS tagging of Lr19, a gene conferring resistance to leaf rust in wheat, Theor. Appl. Genet. 103 $(2001) \quad 618-624$.

[ 26 ] X. Shan, T.K. Blake, L.E. Talbert, Conversion of AFLP markers to sequence-specific PCR markers in barley and wheat, Theor. Appl. Genet. 98 (1999) 1072-1078.

[27] B. Brugmans, R.G.M. van der Hulst, R.G.F. Visser, P. Lindhout, H.J. Van Eck, A new and versatile method for the successful conversion of AFLP markers into simple single locus markers, Nucleic Acids Res. 31 (2003) e55(9 pp).

[2 8] P. Azhaguvel, D. Vidya-Saraswathi, T. Komatsuda, Conversion of AFLP markers linked to the non-brittle rachis locus btrl/btr2 into sTS markers for high-resolution linkage mapping and phylogenetic study using btrl-linked markers in barley, in: Proceeding of the 8 th Gatersleben Research Conference - Genetic Diversity \& Genome Dynamics in Plants, Chateau Meisdorf/IPK Gatersleben, Germany, 2005 , pp. 93. 
[29] R. Görg, K. Hollricher, P. Schulze-Lefert, Functional analysis and RFLP-mediated mapping of the MIg resistance locus in barley, Plant J. 3 (1993) 857-866.

[30] G. Künzel, L. Korzun, A. Meister, Cytologically intergrated physical restriction fragment length polymorphism maps for the barley genome based on translocation breakpoints, Genetics $154(2000) \quad 397-412$.

[31] G. Moore, K.M. Devos, Z. Wang, M.D. Gale, Grasses, line up and form a circle, Curr. Biol. 5 (1995) 737-739.

[32] D.W. Smilde, J. Haluskova, T. Sasaki, A. Graner, New evidence for the synteny of rice chromosome 1 and barley chromosome $3 \mathrm{H}$ from rice expressed sequence tags, Genome 44 $(2001) \quad 361-367$. 


\section{Figure legend}

Fig 1. (A) High-density map of the btrl and btr2 loci in 99 RILs of 'Azumamugi' $x$ 'Kanto Nakate Gold', modified after Komatsuda and Mano (2002) and Komatsuda et al. (2004). All the 23 AFLPs that we sequenced are shown in Table 1. Allelism was confirmed for nine AFLP-STS pairs. ABG047 and ABAO01 are STS markers flanking the btrl and btr2 loci. (B) High-resolution map of the btrl locus in $672 \mathrm{~F}_{2}$ plants of 'Kanto Nakate Gold' 'OUH602. Six STS markers converted from AFLPs were used for the mapping. A physical contig was made for the co-segregating markers. 
Table 1. AFLP markers for the btrl and btr2 loci, their DNA sequences (plus GenBank/EMBL/DDBJ accession numbers), and results of a blastn search

\begin{tabular}{|c|c|c|c|c|c|}
\hline AFLP marker & Dominant parent & Size $(b p)^{a}$ & Acc. No & Blastn with the Genbank & E value $^{\mathrm{b}}$ \\
\hline $\mathrm{e} 04 \mathrm{~m} 55-09$ & $\mathrm{KNG}$ & 202 & \#\#\#\#\#\#\#\# & - & - \\
\hline $\mathrm{e} 05 \mathrm{~m} 15-09$ & $\mathrm{AZ}$ & 204 & \#\#\#\#\#\#\# & - & - \\
\hline e06m49-08 & KNG & 278 & \#\#\#\#\#\#\# & Hordeum vulgare transposon MITE & $9.0 \mathrm{e}-55$ \\
\hline $\mathrm{e} 09 \mathrm{~m} 25-08$ & KNG & 245 & \#\#\#\#\#\#\# & - & - \\
\hline e19m27-11 & KNG & 131 & \#\#\#\#\#\#\#\# & - & - \\
\hline e23m12-13-1 & $\mathrm{AZ}$ & 101 & \#\#\#\#\#\#\# & - & - \\
\hline e23m12-13-2 & KNG & 100 & \#\#\#\#\#\#\#\# & - & - \\
\hline e23m23-07 & KNG & 318 & \#\#\#\#\#\#\# & Hordeum chilense RAPD marker IAS-pHc4-3 & $2.0 \mathrm{e}-22$ \\
\hline e23m44-13 & KNG & 96 & \#\#\#\#\#\#\# & - & - \\
\hline e24m42-08 & $\mathrm{AZ}$ & 285 & \#\#\#\#\#\#\# & Hordeum vulgare ssp. vulgare Morex BAC clone 773K14 & $8.0 \mathrm{e}-06$ \\
\hline e26m58-13 & KNG & 81 & \#\#\#\#\#\#\# & - & - \\
\hline e30m07-09 & $\mathrm{AZ}$ & 204 & \#\#\#\#\#\#\# & - & - \\
\hline e34m11-10 & KNG & 160 & \#\#\#\#\#\#\# & - & - \\
\hline e37m30-10 & KNG & 150 & \#\#\#\#\#\#\# & - & - \\
\hline e39m23-11 & KNG & 133 & \#\#\#\#\#\#\# & Hordeum vulgare Gypsy type retrotransposon BAGY-1 & $5.0 \mathrm{e}-17$ \\
\hline e40m19-08 & KNG & 284 & \#\#\#\#\#\#\#\# & - & - \\
\hline $\mathrm{e} 45 \mathrm{~m} 11-11^{\mathrm{c}}$ & KNG & 143 & \#\#\#\#\#\#\# & - & - \\
\hline e46m23-09 & KNG & 203 & \#\#\#\#\#\#\# & Hordeum vulgare Gypsy type retrotransposon BAGY-1 & $2.0 \mathrm{e}-24$ \\
\hline $\mathrm{e} 48 \mathrm{~m} 02-08$ & KNG & 289 & \#\#\#\#\#\#\# & - & - \\
\hline $\mathrm{e} 50 \mathrm{~m} 12-04$ & KNG & 610 & \#\#\#\#\#\#\# & Triticum turgidum LTR retrotransposon Sabrina & $5.0 \mathrm{e}-09$ \\
\hline e50m21-01 & KNG & 1247 & \#\#\#\#\#\#\# & - & - \\
\hline e53m62-09 & KNG & 237 & \#\#\#\#\#\#\# & Triticum turgidum Gypsy LTR retrotransposon Laura & $2.0 \mathrm{e}-15$ \\
\hline e $57 \mathrm{~m} 10-07$ & $\mathrm{AZ}$ & 318 & \#\#\#\#\#\#\# & Hordeum vulgare chromosome $5 \mathrm{BAC} 635 \mathrm{P} 2$ & $0.0 \mathrm{e}-113$ \\
\hline e58m61-09-1 & KNG & 223 & \#\#\#\#\#\#\#\# & - & - \\
\hline e60m22-07 & KNG & 365 & \#\#\#\#\#\#\# & Aegilops tauschii LZ-NBS-LRR class RGA, HCBT & $2.0 \mathrm{e}-35$ \\
\hline e62m32-08 & $\mathrm{AZ}$ & 243 & \#\#\#\#\#\#\# & Hordeum roshevitzii BARE-1 long terminal repeat DNA & $1.0 \mathrm{e}-47$ \\
\hline
\end{tabular}

${ }^{c}$ A blastn search against TIGR database (Gramineae Repeat) showed a homology with Hordeum vulgare Sukkula retrotransposon with a $p$ value of $1.1 \mathrm{e}-08$ 
Table 2. STS markers for the btr1 and btr2 loci, and their chromosomal locations and polymorphism

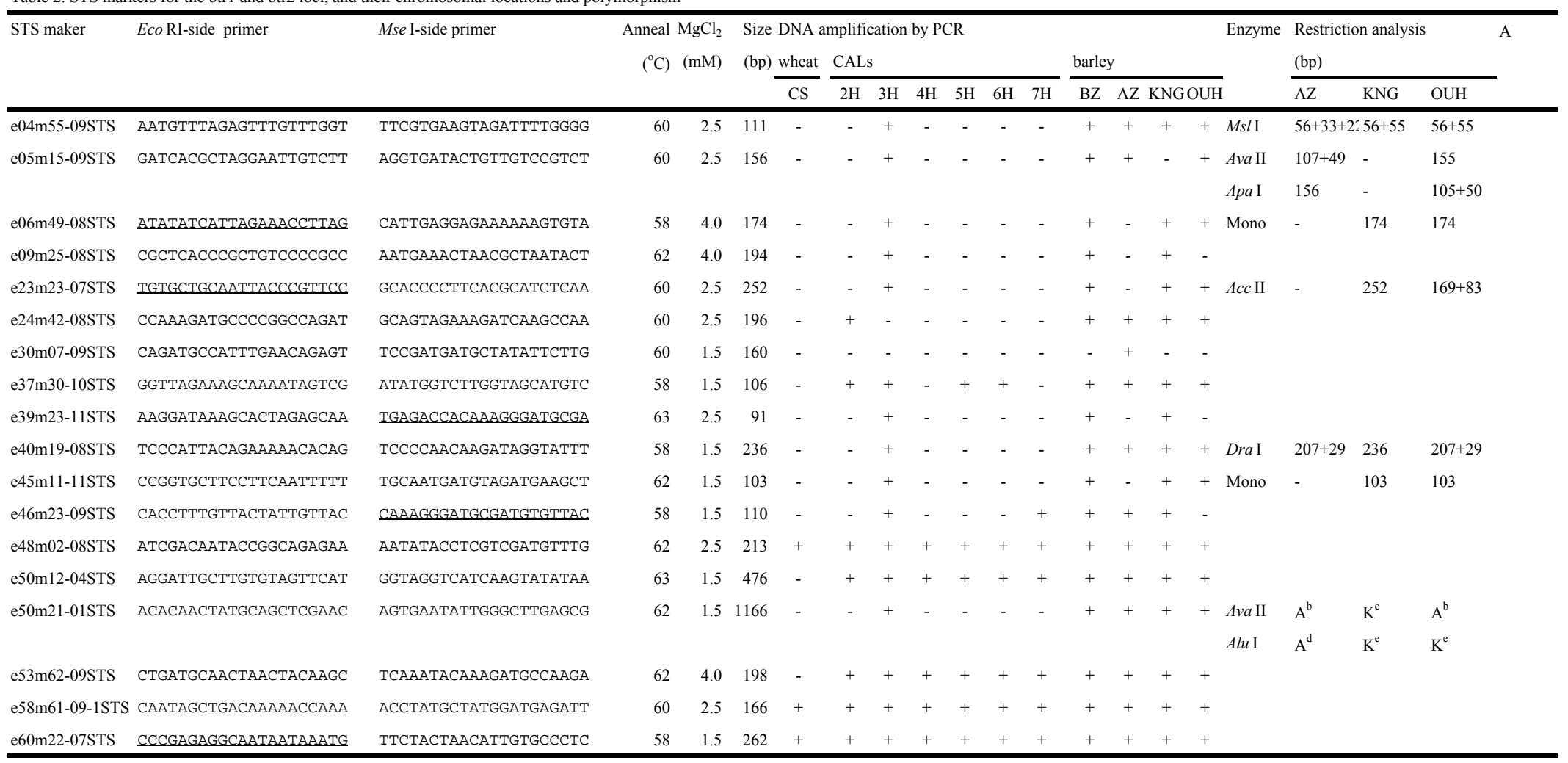

${ }^{a}$ Between AFLPs and STSs tested using AZ x KNG RILs (no. of identical genotype/no. of RILs tested)

${ }^{\mathrm{b}} 588+267+259+52,{ }^{\mathrm{c}} 532+267+259+56+52,{ }^{\mathrm{d}} 561+323+239+29+14,{ }^{\mathrm{e}} 561+323+161+78+29+14$

Primers with underlines include repeated sequences 


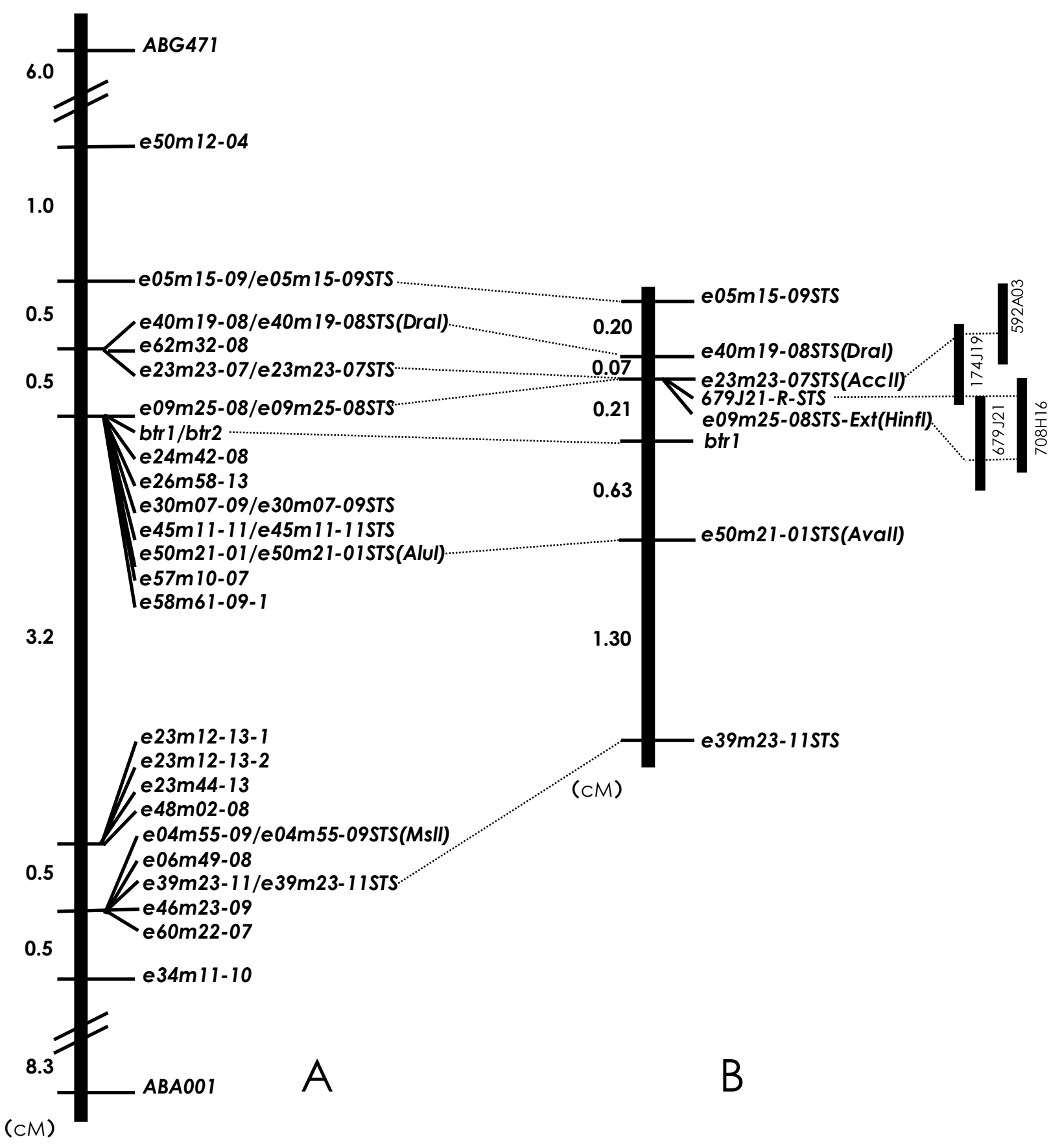

